\title{
Estimates of dispersion from clustered-drifter deployments on the southern flank of Georges Bank
}

\author{
J.P.Manning ${ }^{1} \&$ J.H.Churchill ${ }^{2}$ \\ ${ }^{1}$ National Oceanic and Atmospheric Administration's Northeast Fisheries Science Center, \\ Woods Hole, MA 02543 \\ ${ }^{2}$ Department of Physical Oceanography, \\ Woods Hole Oceanographic Institution, Woods Hole, MA 02543 \\ $3 / 21 / 06$
}




\begin{abstract}
Data from 16 clustered-drifter deployments are used to examine horizontal dispersion on the southern flank of Georges Bank. The spreading rates of all clusters have an average of $1.6 \mathrm{~km}$ $\mathrm{d}^{-1}$ with a standard deviation of $1.8 \mathrm{~km} \mathrm{~d}^{-1}$. Both "effective" and "apparent" diffusivities are calculated for each cluster. Their ranges (i.e., -54 to $757 \mathrm{~m}^{2} \mathrm{~s}^{-1}$ for effective diffusivity) are related to differences in cluster size and proximity to the tidal mixing front. Cross-bank convergence is documented for nearly $40 \%$ of the clusters. This occurs especially for clusters with centroids within $10 \mathrm{~km}$ of the tidal mixing front location, as deduced from conductivity, temperature, and depth transects (CTD) conducted concurrently with the cluster deployments. Estimates of turbulent dispersion (distinct from shear effects) are derived by the method of Okubo and Ebbysmeyer (Okubo, A. and Ebbesmeyer, C.C., 1976. Determination of vorticity, divergence, and deformation rates from analysis of drogue observations. Deep-Sea Res., 23, 349-352). The results reveal that the effects of horizontal shear are important in spreading of larger drifter clusters. Often the impact of shear is evidenced by the track of a lone drifter that separates from a cluster as it is entrained into the current of the shelf-edge front or the tidal mixing front. Cluster dispersion is time dependent as evidenced by a significant modulation of cluster size at the $\mathrm{M}_{2}$ tidal frequency. This modulation is due to the spatial variation of tidal currents over the southern flank of Georges Bank and is closely reproduced by immersing drifter clusters into the flow field of a Georges Bank tidal model.
\end{abstract}

Keywords: Dispersion, Drifters, Tidal Front, Georges Bank, Gulf of Maine, Fish Larvae 


\section{Estimates of Dispersion}

\section{Introduction}

Studies of larval retention/loss on Georges Bank in the late 1990's have attempted to assess the impact of biological (i.e., mortality, fecundity, starvation) and physical processes (i.e. advective shear, turbulent dispersion) on larval populations over the bank. The focus of this paper is on the latter: physical mechanisms that may govern the distribution, dispersion, and ultimate fate of a larval patch. For circulation models to accurately describe the fate of larvae, the parameterization of dispersion needs to be realistic. Empirical values of eddy diffusivity, used to parameterize horizontal mixing and dispersion in models, are typically specified and adjusted for the particular regions, water depths, and processes under investigation.

Unfortunately, very little information about physical dispersion is available from field observations. Several studies have attempted to estimate horizontal dispersion rates, many using clustered-drifter deployments. Early studies by Reed (1971) and Chew and Berberian (1971) provided estimates of horizontal divergence based on the relative motion of drifters deployed in the Alaskan Stream and Gulf Stream, respectively. Other studies, such as Pingree et al. (1974) and Matthews et al. (1993), estimated dispersion with particular emphasis on episodic instances of convergence. In the latter study (using radar), convergence was noted in 4 out of 20 days of observations. Using data from clustered drifters and employing theory from Okubo (1971) and Zimmerman (1986), Smith (1989) calculated limited residence times ( $\sim 14$ days) on Brown's Bank due to advective loss and, especially, due to dispersive processes. Drinkwater and Loder (2001, henceforth "DL2001") estimated high dispersion rates over Georges Bank, but also noted instances of convergence in the vicinity of tidal mixing fronts. Using a combination of dye and detailed temperature section data from Georges Bank, Houghton (2001) made estimates of crosstidal front flow, and computed a near-bottom, on-bank flow of $1.9 \mathrm{~cm} \mathrm{~s}^{-1}$ over the southern flank. 


\section{Estimates of Dispersion}

The issue of exchange across the shelf-break front of the Middle Atlantic Bight was addressed recently by Lozier and Gawarkiewicz (2001). From examination of the tracks of nearly a hundred individual drifters entrained into the shelf-break jet, they found evidence of episodic entrainment into, and detrainment out of, the shelf/slope boundary. Advection towards the oceanic side of the boundary was dominant, especially in winter months.

Here we examine dispersion and diffusion on Georges Bank using data from drifter clusters deployed over 1995-1999 as part of the Georges Bank GLOBEC (GLOBal ocean ECosystem dynamics) program. Our work is similar to that of DL2001, who estimated horizontal mixing properties using data from 17 drifter clusters deployed on the northern flank of Georges Bank during 1988-1989. Our study focuses on the southern flank of Georges Bank, which differs dynamically from the narrower and more steeply inclined northern flank in several important ways. Both tidal and mean currents tend to be stronger on the northern flank than on the southern flank (Brown and Moody, 1987; Butman and Beardsley, 1987; Brink et al., 2003). Perhaps most importantly for our study is the contrast in hydrographic structure over the northern and southern flanks. During the spring and summer, there are typically two distinct fronts found over the southern flank: a shelf-edge front and a tidal mixing front. The latter is located near the 60-m isobath (Garrett et al, 1978) and is typically on the order of $40 \mathrm{~km}$ onbank of the shelf-edge front (Flagg, 1987). By contrast, the bank-edge and tidal mixing front are often not clearly separated over the northern flank during the spring and summer (Flagg, 1987).

Using the methods employed by DL2001, we use the southern flank drifter cluster data to estimate measures of horizontal patch spreading, including the "effective" and "apparent" 


\section{Estimates of Dispersion}

diffusivities. We also examine phenomena not considered in detail by DL2001. These include: the effects of spatially variable tidal motions on cluster size and the manner in which cross-bank dispersion is influenced by cluster proximity to the tidal mixing front.

\section{Data/Methods}

Drifters used in these deployments consisted of cylindrical canisters (typically $\sim 0.2-\mathrm{m}$ diameter $\mathrm{x}$ 1.0-m height), housing batteries and electronics, with attached ARGOS/GPS antennae (Figure 1). For some of the earliest deployments, canisters were also fitted with a VHF antenna for twoway communications with the ship, but these were discontinued in latter years. Four small $(0.1 \mathrm{~m})$ Styrofoam spheres on two fiberglass rods served as canister floatation. The spheres were affixed so that the canisters were completely submerged and only the antennae extended above the sea surface. Drifters were fitted with a holey sock drogue suspended by $3 / 16$ " plastic coated wire beneath a $0.3-\mathrm{m}$ diameter surface float. The electronic canister was tethered to the surface float with several meters of polypropylene line. The cylindrical cloth drogues had dimensions of either 1 x $10 \mathrm{~m}$ or $1.6 \times 6 \mathrm{~m}$. While changes in canister and drogue configuration were implemented throughout our study, all drifters conformed to the WOCE standard (Sybrandy and Niiler, 1991) of a minimum 40:1 drag ratio. The GPS sampling rate was in the range of 5-15 minutes. The GPS position data from the drifters were obtained through system ARGOS.

\section{Figure 1 here}

A set of data processing steps were conducted on the drifter position data prior to the calculations of dispersion:

- Gaps of less than one half the $\mathrm{M}_{2}$ tidal cycle, often resulting from missed data transmissions to ARGOS satellites, were filled by manually inserting the missing points on plots of the observed drifter paths. This procedure needed to be carried out for 


\section{Estimates of Dispersion}

approximately one quarter of the drifter position records.

- High-frequency noise in the GPS position fixes was removed by conducting a hourly-running average of the latitude and longitude series.

- $\quad$ Points resulting in unrealistic velocities were removed, with cut-off values ranging from 75 to $200 \mathrm{~cm} \mathrm{~s}^{-1}$ depending on the deployment location and drogue depth. This phase of the data checking also was conducted graphically with subjective decisions made on a spike-by-spike basis in a manner similar to that followed by the standard Acoustic Doppler Current Profiler editing procedure (Humman, 2005).

- The time derivative of the velocity (i.e., acceleration) time series was checked for extraneous values. After some experimentation, a velocity change of $0.005 \mathrm{~m} \mathrm{~s}^{-1}$ per 10 minute sample was chosen as a cutoff point.

The processed data are served through the Georges Bank GLOBEC homepage at http://globec.whoi.edu/globec.html. Details of individual deployments are documented in cruise reports also available on the homepage and in published accounts of process studies over Georges Bank (e.g., Manning et al. 2001; Lough and Manning 2001; and Aretxabaleta et al. 2005). Cluster locations and individual cluster tracks are shown in Figures 2 and 3, respectively. The drogue depths and cluster statistics are listed in Table 1 with clusters segregated into shallow (drogue centered $<=15 \mathrm{~m}$ ) and deep (drogue centered $>15 \mathrm{~m}$ ) layers. ${ }^{1}$

Figures 2 and 3 here.

To quantify the change in cluster size, we defined a mean along-bank and cross-bank displacement from the cluster centroid at each time step as:

\footnotetext{
${ }^{1}$ While Cluster 9 was removed from these tabulated statistics (given that there was only one drogue located in each of the two layers), it was used in other aspects of the study below. A third drifter in cluster 9 lost its drogue.
} 


\section{Estimates of Dispersion}

$$
D_{x}=\frac{1}{n} \sum_{n=1}^{n}\left|x_{i}\right| \quad ; \quad D_{y}=\frac{1}{n} \sum_{n=1}^{n}\left|y_{i}\right|
$$

where $x_{i}$ and $y_{i}$ are the along-bank and cross-bank displacements of the $i$-th drifter relative to the cluster centroid. For all clusters, the positive "along-bank" axis was oriented towards $60^{\circ} \mathrm{T}(e . g$., in a ENE direction) and the positive "cross-bank" directions was oriented towards $330^{\circ} \mathrm{T}(e . g$, in a NNW direction).

Calculation of effective diffusivity was carried out according to:

$$
K_{e}=1 / 4 \frac{\partial \sigma^{2}}{\partial t}
$$

where $\sigma^{2}$ is the "mean squared displacement" from the centroid given by:

$$
\sigma^{2}=\frac{1}{n} \sum_{i=1}^{n}\left(x_{i}^{2}+y_{i}^{2}\right)
$$

We take $K_{e}$ as a measure of bulk dispersion that includes the effects of both turbulent diffusion and velocity shear. The values of $K_{e}$ tabulated here (Table 1) are the means of $K_{e}$ values determined by applying the above equations at each time step of a cluster's position data.

Both Smith (1989) and DL2001 provided estimates of another quantity referred to as the "apparent eddy diffusivity" calculated as:

$$
K_{a c}=\frac{\sigma^{2}}{4\left(t_{0}+t^{\prime}\right)}
$$

where $t_{0}$ is the estimated time it takes for a point source to disperse to the initial observed size of the cluster and $t^{\prime}$ is the time since cluster release. Based on Okubo's (1974) conjecture that patch size increases from a point source as $t^{3}$, DL2001 estimated $t_{0}$ using the relation $\sigma^{2}=c_{l} \varepsilon t^{3}$. This 


\section{Estimates of Dispersion}

gave $t_{0}=\left(\sigma_{0}^{2} / c_{1} \varepsilon\right)^{1 / 3}$, where $\sigma_{0}^{2}$ is the initial mean squared displacement of the cluster. To estimate $t_{0}$, we evaluated this relationship taking $c_{1} \varepsilon$ as $5.4 \times 10^{-10} \mathrm{~m}^{2} \mathrm{~s}^{-3}$, a value determined by Okubo (1974) and used by DL2000.

An alternative, empirical, formula for apparent diffusivity was derived by Okubo (1971) using data from 20 sets of diffusion experiments reported in the literature. Smith (1989) converted the proportionality constant in Okubo's expression to provide units of $\mathrm{m}^{2} \mathrm{~s}^{-1}$ for diffusivity, giving:

$$
K_{a e}=0.579 \lambda^{1.15}
$$

where the length scale, $\lambda(\mathrm{km})$, is the size of the cluster and is equal to $3 \bar{\sigma}$ (averaged over the lifetime of the cluster). We note that this empirically determined apparent diffusivity $\left(K_{a e}\right)$ is distinguished symbolically from the apparent diffusivity computed from drifter cluster data $\left(K_{a c}\right)$ defined above.

The difference between the calculated measures of dispersion $\left(K_{e}\right.$ vs. $\left.K_{a c}\right)$ is subtle. $K_{e}$ is derived from actual changes in cluster size, whereas $K_{a c}$ relies on theoretical relationships to cluster size. While the former is preferred for documenting cases of convergence (as it allows negative values), the latter $\left(K_{a c}\right)$ is included for comparisons with published values (e.g., Okubo, 1971).

A method often used to distinguish between diffusive and velocity shear effects on cluster growth is that of Okubo and Ebbesmeyer (1976), henceforth "OE76". In this method, the velocity of a drifter centroid ( $u$ and $v$ ) is expanded in a Taylor series:

$$
u_{i}(t)=\bar{u}+\frac{\partial \bar{u}}{\partial x} x_{i}+\frac{\partial \bar{v}}{\partial y} y_{i}+u^{\prime \prime}{ }_{i}
$$




$$
v_{i}(t)=\bar{v}+\frac{\partial \bar{v}}{\partial x} x_{i}+\frac{\partial \bar{v}}{\partial y} y_{i}+v^{\prime \prime}{ }_{i}
$$

This results in a linear system of equations that can be solved (see OE76) where $\bar{u}$ and $\bar{v}$ represent the mean of the drifters' velocities at each time step, and the residuals, $u^{\prime \prime}$ and $v^{\prime \prime}$, represent the turbulent component. The resulting estimate of diffusivity in a Cartesian coordinate system is:

$$
\begin{aligned}
& K_{x}(t)=c \sigma_{u^{\prime \prime}} \sigma_{x} \\
& K_{y}(t)=c \sigma_{v^{\prime \prime}} \sigma_{y}
\end{aligned}
$$

where:

$$
\begin{aligned}
\left(\sigma_{u^{\prime \prime}}, \sigma_{v^{\prime \prime}}\right) & =\left[\frac{1}{n-1}\left(\sum_{1}^{n}\left(u_{i}^{\prime \prime}\right)^{2}, \sum_{1}^{n}\left(v^{\prime \prime}{ }_{i}\right)^{2}\right)\right]^{1 / 2} \\
\left(\sigma_{x}, \sigma_{y}\right) & =\left[\frac{1}{n-1}\left(\sum_{1}^{n}\left(x_{i}\right)^{2}, \sum_{1}^{n}\left(y_{i}\right)^{2}\right)\right]^{1 / 2}
\end{aligned}
$$

A difficulty with applying this method is the need to choose a value for the proportionality constant "c", which has been set between 0.1 and 1.0 in other studies. Following Smith (1989) and DL2001, the former value was chosen in order to be consistent with most other estimates in recent literature.

In cases where CTD measurements were acquired along a cross-bank section in the vicinity of a cluster, the cross-bank distance of each drifter relative to the tidal mixing front was calculated. To do this, we assumed that the distance of the front relative to the $60-\mathrm{m}$ isobath was constant over the lifetime of the drifter cluster and over the area the cluster traversed. We used the 60-m 


\section{Estimates of Dispersion}

isobath as a marker because it has been associated with the theoretical location of the tidal mixing front (Garrett et al, 1978) and because most of the clusters were in the proximity of the 60-m isobath. Working with this assumption, the following quantities were calculated: 1) the location of maximum cross-bank gradient in sigma-t at the depth of the drogue, 2) the distance of this location to the $60-\mathrm{m}$ isobath $\left(F_{60}\right)$, and 3 ) the distance of each drifter (at each fix) to the 60$\mathrm{m}$ isobath $\left(d_{60}\right)$. With our working assumption, $\left|F_{60}-d_{60}\right|$ gave the "distance from front" $\left(d_{\text {Front }}\right)$ of each drifter fix. An average $d_{\text {Front }}$ was calculated for each drifter. However, before calculating this average, the $d_{\text {Front }}$ time series was truncated to be an integer multiple of the $\mathrm{M}_{2}$ tide in order to avoid the biasing due to the inclusion of partial tidal cycles.

A simple model to numerically follow particles through an empirically-derived tidal flow was used to investigate the effect of tides on cluster size. The tidal flow model (Dunn, 2002) provided estimates of the barotropic tide over Georges Bank based on ADCP measurements acquired over 5 years during more than 100 research cruises. With this model, estimates of the major tidal constituents $\left(\mathrm{M}_{2}, \mathrm{~S}_{2}, \mathrm{~N}_{2}, \mathrm{~K}_{1}\right.$ and $\left.\mathrm{O}_{1}\right)$ allowed for the computation of empirical tidal velocities for any time and location on Georges Bank. These velocities were used to simulate particle tracks advected by the tide and by a typical mean flow of $13.1 \mathrm{~cm} \mathrm{~s}^{-1}$ towards the southwest $\left(225^{\circ}\right)$.

An issue of importance in assessing our estimates of dispersion is that of "slippage". Slippage refers to a drifter's inability to accurately follow a water parcel. It results from a combination of wind forcing on the above-surface expression of the drifter, drag on the submerged surface buoy and tether, and oscillatory motions due to surface waves. Typical values reported in the literature (Geyer, 1989, Niiler et al, 1995) range over $0.6-4 \mathrm{~cm} \mathrm{~s}^{-1}$ for holey sock drogues and 


\section{Estimates of Dispersion}

usually depend on the wind forcing. A recent comparison of the drogued drifters with dye patches on Georges Bank (Proehl, et al 2005), reveal low values of slippage that are well within this range. It is important to note that in this study we are primarily interested in the relative motion of drifters, and that all drifters maintained drag ratios that were nearly equivalent, and always $>40: 1$. Since the wind/wave field can be taken to be nearly uniform over the scale of the clusters, the effect of slippage on the relative motion of drifters to one another should be relatively small.

\section{Results}

As exemplified in Figure 4, the mean radial distance of the drifters from their cluster centroid ( $\sigma$ defined earlier in methods section) shows evidence of both cluster divergence (e.g., cluster \#3) and cluster convergence (e.g. cluster \#14). The mean displacements of drifters parallel (alongbank) and perpendicular (cross-bank) to the local bathymetry $\left(D_{x}\right.$ and $\left.D_{y}\right)$ were calculated for each cluster in both shallow $(<=15 \mathrm{~m})$ and deep $(>15 \mathrm{~m})$ layers (Figure 5). There is evidence of cross-bank convergence in $40 \%$ of the clusters (labeled in Figure 5).

Figures 4 and 5 here.

A plot of drifter displacements relative to the cluster centroid (Figure 6) provides an alternative view of dispersive processes. The predominance of along-bank spreading can be seen in most deployments $(1-5,7,9,10$ and 12) whereas mesoscale eddy processes are evidently at work in the others $(6,8,11$ and 13-16).

Figure 6 here.

The calculations of effective diffusivity, $K_{e}$, resulted in values ranging from -54 to $757 \mathrm{~m}^{2} \mathrm{~s}^{-1}$; 


\section{Estimates of Dispersion}

while apparent diffusivity, $K_{a c}$, values were limited to a range of 3 to $139 \mathrm{~m}^{2} \mathrm{~s}^{-1}$. The increase of $K_{a c}$ with cluster size is closely aligned with that observed by DL2001 (Figure 7). Both our values of $K_{a c}$ and those of DL2001 tend to fall just below $K_{a e}$ (Okubo's empirical relationship) for smaller clusters and well above $K_{a e}$ for larger clusters.

Figure 7 here.

The values of $K_{x}$ and $K_{y}$ determined by the OE76 method appear in Table 1. For all but one cluster (\#15), there is a significant difference between the OE76 measure of diffusion $\left(\left[K_{x}+K_{y}\right] / 2\right)$, from which horizontal current shear effects have been theoretically removed, and $K_{e}$, which includes the effects of horizontal shear. The impact of shear is most noticeable in cluster \#2, as easily seen in the plot of the cluster's drifter tracks (Figure 3a). This shows one drifter separating from the cluster as it is entrained in the shelf-edge frontal jet and rapidly carried downstream (at $\left.>40 \mathrm{~cm} \mathrm{~s}^{-1}\right)$.

Because of the small ensemble size, we cannot use the values of $K_{x}$ and $K_{y}$ to definitively support a claim of anisotropic diffusion. Clusters 2 and 3, with $\lambda$ of roughly 43 and $16 \mathrm{~km}$ respectively, exhibit stronger along-bank diffusion $\left(K_{x}>K_{y}\right)$. However, two smaller-sized clusters $(\lambda<7 \mathrm{~km})$ appear to be diffusing more rapidly in the cross-bank direction $\left(K_{x}<\mathrm{K}_{\mathrm{y}}\right)$.

For many clusters, the variation of mean cross-bank displacement $\left(D_{y}\right)$, relative to the cluster centroid exhibits a clear semidiurnal signal which is roughly $90^{\circ}$ out of phase with the crossbank velocity of the cluster centroid (Figure 8). This is most likely due to modulation of the cluster variance by spatial variation of the $\mathrm{M}_{2}$ tidal flow. Consider, for example, the relative displacement of two particles with initial positions at different isobaths on the southern flank. Because of the shoaling of the $\mathrm{M}_{2}$ tide, the shallower particle will always be subject to a stronger 


\section{Estimates of Dispersion}

$\mathrm{M}_{2}$ tidal velocity than the deeper particle. This situation will cause the particles to move apart when the tide is directed on-bank, and to converge when the tide is directed off-bank.

Figure 8 here.

We simulated this phenomenon by immersing particles into the flow field specified by the Dunn (2002) multi-constituent empirical tidal model. For comparison with a particular cluster's behavior, the particles were set out at the same positions and times as the cluster's drifters. The simulated and observed semidiurnal variation of the clusters' cross-bank displacement were always in close agreement. Consider, for example, the simulated spreading of cluster 3 (Figure 9). While the simple tidal model (without dispersive effects) obviously does not reproduce the observed cluster growth, it does generate semidiurnal modulations of the cluster size that are similar in phase and magnitude to the observed modulations. We conclude that these observed modulations are due to the spatial variation of tidal amplitude over the southern flank.

Figure 9 here.

To quantify the impact of the spatial variability of tidal velocity on the change in cross-bank cluster size, we computed high-pass filtered time series of the observed $D_{y}$ series. These were generated by computing a low-passed filtered $D_{y}$ series using a $24-\mathrm{hr}$ box-car filter, and then subtracting this filtered series from the original $D_{y}$ series. The variances of these high-passed filtered series are primarily due to the $\mathrm{M}_{2}$ modulation. The ratio of the root-mean square (RMS) of the high-passed filtered and original $D_{y}$ series (with the mean removed from each) thus gives a measure of the impact of the tidally-driven cluster size modulation on the overall cross-bank variability of cluster size. Including all clusters, these ratios have a mean of 0.54 with a standard deviation of 0.23 . Clearly, the spatial variation of the $\mathrm{M}_{2}$ tide has a significant impact on the cross-bank variation in cluster size. 


\section{Estimates of Dispersion}

Investigation of water mass property changes associated with moving drifters indicate that, in most cases, drifters tend to follow isopycnals with less than a 0.02 sigma-t $\mathrm{d}^{-1}$ variation (Figure 10). Most of the change in the properties of water measured near a particular drifter is associated with a temperature increase, which averages approximated $0.16{ }^{\circ} \mathrm{C} \mathrm{d}^{-1}$. In the case of the SJ9507 and OC301 cruises, temperature probes (attached to the drifters themselves) recorded 0.36 and $0.06{ }^{\circ} \mathrm{C} \mathrm{d}^{-1}$, respectively, in close agreement with the CTD-derived property changes. Figure 10 here.

\section{Discussion}

An issue worthy of further exploration is the extent to which the variability of dispersion noted above may be due to the proximity of the drifters to frontal features. Figure 11 depicts the drogue positions relative to the cross-bank density structure near the time of deployment. Drogue positions acquired within three days of the mean time of the CTD section are posted relative to the location of the front. In this figure, the center of the front is defined as the position of maximum cross-shelf gradient in sigma-t at 30-m depth. In cases in which there is a strong frontal structure near the surface, as seen in May 1995 and April 1999, some drogues appear to converge towards the front; but a general conclusion is not possible given the complexity of the frontal structure. In some cases there are apparently multiple surface fronts. The cases of April 1997 and May 1997 are especially difficult to diagnose given the lack of CTD observations from the off-bank side of the clusters. The two shallow drogues in the May 1999 case appear to be converging towards two distinct near-surface fronts. The deeper drogues in the May 1999 case are located between a subtle tidal mixing front to their north and a deep shelf-slope front to their 


\section{Estimates of Dispersion}

south. This is an interesting situation which, in some cases, may cause cluster divergence with drifters moving to one front or the other.

\section{Figure 11 here.}

Modeling studies have indicated a tendency of convergence toward the tidal mixing front near the surface and bottom (e.g., Garrett and Loder, 1981; Chen and Beardsley, 2002). The limited set of data for which cluster proximity to the front can be determined suggest that the tendency for cross-bank cluster convergence (noted in Figure 5) may depend, in part, on the cluster's position relative to the front. When daily averaged change in cross-bank cluster extent is plotted against cluster-mean distance from the front (posted as the blue number on each panel of Figure $11)$, a tendency is indicated in which drifters very close to the front $(<10 \mathrm{~km})$ converge and those located further away from the front diverge (Figure 12).

Figure 12 here.

As noted above, our measurements indicate horizontal shear near the shelf-edge front can be a mechanism for drifter patch dispersion. This is revealed by the analysis of the tracks of cluster \#2 in which the bulk dispersion coefficients $\left(K_{e}\right.$ and $\left.K_{a c}\right)$ are significantly greater than dispersion coefficients that account for turbulence alone $\left(K_{x}\right.$ and $\left.K_{y}\right)$. In all cases, this difference is due to the track of a lone drifter which is entrained into the shelf-edge frontal current (Table 1; Figure 3a).

To further address questions of slippage and mixing, the T-S relation of the water masses sampled in drifter-following operations was examined. In these operations, particular drifters were followed for multiple tidal cycles with CTD casts acquired near the drifters. While estimates of property changes per day were calculated (Figure 10), much of this variability likely resulted from subtle horizontal gradients in the vicinity of the drifters. Given the complex small- 


\section{Estimates of Dispersion}

scale density structure present over most of the southern flank, it is nearly impossible to conduct "patch following" operations in order to detect changes over time when so much spatial variability exist. Even if the drifter itself were internally recording values, slippage over a few kilometers may advect the unit into different water mass properties. To cast a net, CTD apparatus, or any other oceanographic instrumentation in the same body of water day after day can be done with very limited success on Georges Bank.

Our study has revealed the importance of cross-bank variation in tidal current strength in modulating the size of drifter clusters (Figures 8 and 9). Clearly, it is necessary to measure dispersion on Georges Bank for at least a full day in order to estimate dispersion rates due to processes other than tidal current variation. The action of tidal motions in modulating the relative positions of particles may have important implications in biological interactions over the southern flank. It will, for example, cause the relative distance between predator and prey confined within a patch to vary over the course of a semidiurnal tidal cycle. Recently, Cotté and Simard (2005) have document how the interaction of tidal flow with topography leads to the concentration of krill in the St. Lawrence Estuary.

In light of the high frequency variations in cluster extent, it is useful to quantify cluster growth with a simple index of patch spreading defined as the "mean change in cluster size per day", with cluster size defined as the mean radial distance of the drifters from the cluster centroid. We have determined this growth rate index as the change in cluster size, from the start to end of each deployment, divided by the deployment duration. The range of values is fairly broad for our ensemble of drifter clusters. When averaged over all clusters, the growth rate is $1.6 \mathrm{~km} \mathrm{~d}^{-1}$ with a standard deviation of $1.8 \mathrm{~km} \mathrm{~d}^{-1}$. 


\section{Estimates of Dispersion}

It is important to emphasize that our results apply to a tracer confined to a single horizontal level. As demonstrated in a modeling study of dispersion on the northern flank of Georges Bank by Proehl et al. (2005), the degree of dispersion of particles free to move in 3-dimensions is sensitive to the vertical eddy diffusivity and vertical shear of horizontal velocity. A patch of such particles subjected to even a localized area of vertical shear (such as the vicinity of a tidal mixing front jet) will tend to rapidly disperse. Proehl et al. (2005) also note that this dispersion is a highly episodic and event-driven process, which is difficult to quantify in the field. This sort of spatially-variable dispersion likely exists throughout most of the coastal oceans.

As documented by Teng (2002), the effect of topographic variations also impacts drifter cluster divergence. Using a set of clustered drifters off the Taiwan coast, Teng finds order-ofmagnitude differences in dispersive processes over a relatively small region due to subtle variations in bathymetry. This highlights a serious uncertainty in the calculations presented here given that a single bathymetric alignment $\left(60^{\circ}\right)$ was used to define the along-bank axis. Sensitivity studies conducted using along-bank orientations of $75^{\circ}$ and $45^{\circ}$ resulted in the same general conclusions with regard to the percentage of converging clusters (40-50\%), the tidallydriven modulation of cross-bank cluster size and the agreement with DL2001. The topographic angle does obviously become significant in calculations of "cross-bank displacement" (as in the transects of Figure 11). To conduct this analysis precisely, however, one may actually need to consider a time-varying topographic angle (i.e., adjusted temporally for each cluster) to account for the movement of clusters over small-scale bathymetric features. There are also questions of which isobath to consider and how skewed the tidal front axes might be relative to the chosen isobath. These are complexities beyond the present study but worth considering in future 


\section{Estimates of Dispersion}

dispersion studies.

\section{Summary}

Sixteen clustered-drifter deployments on the southern flank of Georges Bank (1994-1999) provide evidence of a variety of processes resulting in both cross-bank convergence and divergence in the region of the tidal front. The mean overall spreading of the clusters is $1.6 \pm 1.8$

$\mathrm{km} \mathrm{d}^{-1}$. Approximately $40 \%$ of the clusters, primarily those with centroids near $(\sim 10 \mathrm{~km})$ the tidal front location (as defined by CTD section data), converge toward the front.

Our estimates of effective and apparent diffusivities vary as a function of cluster size in a manner very similar to that observed on the northern flank of Georges Bank by Drinkwater and Loder (2001). Both our data and those of Drinkwater and Loder give effective diffusivities close to Okubo's (1971) empirical relationship for small cluster sizes and are much higher than Okubo's relationship for larger cluster sizes.

The enhanced diffusivity observed at large cluster size appears to be principally the result of shear in horizontal velocity. Applying the Okubo and Ebbesmeyer (1976) method to expand the velocity field into mean, shear-dependent, and turbulent components allow for the computation of horizontal diffusivity without the effects of shear. The dispersion coefficients determined from the Okubo and Ebbesmeyer method clearly reveal the importance of horizontal shear in the spreading of larger drifter clusters. For these clusters, the impact of shear is often dominated by the track of a lone drifter that parts company with the rest of its cluster through entrainment into the current of the shelf-edge front or the tidal mixing front. 


\section{Estimates of Dispersion}

The dispersive processes are also seen to be time-dependent with a significant periodic modulation at the semidiurnal frequency. This modulation is due principally to the spatial variation of $\mathrm{M}_{2}$ tidal current amplitude in the cross-bank direction and is reproduced by simulating drifter motion in a flow field specified by the model of Dunn (2002). Overall, the $\mathrm{M}_{2}$ tidal modulation of cluster size accounts for roughly $50 \%$ of the variation in the cross-bank extent of the clusters. 


\section{Acknowledgements}

The authors would like to thank the ship captains and crews of the R/V ALBATROSS, ENDEAVOR, OCEANUS, SEWARD JOHNSON, and EDWIN LINK II for the skillful maneuvering required to deploy and recover drifters, often under adverse conditions and limited visibility. Thomas Wilson, of Brightwaters Instruments Coorporation, offered technical assistance with drifter setup and tracking. Thanks go to Jim Ledwell, Miles Sundermeyer, David Mountain, Bob Beardsley, and Ron Schlitz who offered helpful comments on earlier versions of this manuscript. This paper was also greatly improved through the comments and suggestions of two anonymous reviewers. The work carried out at WHOI was supported by the U.S. National Science Foundation under grants OCE-98-06498, OCE-96-32357, OCE98-06397 and OCE0227679. The effort at the Woods Hole NMFS was funded through a grant from the NOAA Coastal Ocean Program. WHOI contribution number 11380. 


\section{Estimates of Dispersion}

\section{References}

Aretxabaleta, A., J.P. Manning, F.E. Werner, K. Smith, B.O. Blanton, and D.R. Lynch, 2005. Hincasting May 1999 on the Southern Flank of Georges Bank: frontal circulation and implications. Cont. Shelf Res, 25 849-874.

Brink, K.H., R. Limeburner, and R.C. Beardsley, 2003. Properties of flow and pressure over Georges Bank as observed with near-surface drifters. J. Geophys. Res. Vol. 108: C11: 8001

Brown, W.S. and J.A. Moody, 1987. Tides. In: R.S. Backus (Ed), Georges Bank.. Massachusetts Institute of Technology, Cambridge, Ma. pp 100-107.

Butman, B. and R.C. Beardsley, 1987. Long-term observations on the southern flank of Georges Bank. Part I: Description of the seasonal cycle of currents, temperature, stratification, and wind stress. J. Phys. Oceanogr., 17(3) 367-384.

Chen, C. and R.C. Beardsley, 2002. Cross-frontal water exchange on Georges Bank: Some results from a U.S. GLOBEC/Georges Bank program model study. J. Oceanogr., 58, 403-420.

Chew, F. and G.A. Berberian, 1971. A determination of horizontal divergence in the Gulf Stream off Cape Lookout. J. Phys. Oceanogr., 1, 39-44.

Cotté, C. and Y. Simard, 2005. Formation of dense krill patches under tidal forcing at whale feeding hot spots in the St. Lawrence Estuary. Mar. Ecol. Prog. Ser. 288, 199-210.

Drinkwater, K.F and J.W. Loder, 2001. Near-surface horizontal convergence and dispersion near the tidal-mixing front on Northeastern Georges Bank. Deep-Sea Res. II, 48, 311-339.

Dunn, M., 2002. A description of the barotropic tide on Georges Bank based upon five years of shipboard ADCP observations. Masters Thesis. State University of New York at Stony Brook. pp. 1-47. 


\section{Estimates of Dispersion}

Flagg, C.N., 1987. Hydrographic Structure and variability, In: R.H. Backus (Ed), Georges Bank, MIT Press, Cambridge, Ma. pp. 108-124.

Garrett, C.J.R., J.R.Keeley, and D.A. Greenberg, 1978. Tidal mixing vs thermal stratification in the Bay of Fundy and Gulf of Maine. Atmosphere-Oceans, 16(4), 403-423.

Garrett, C.J.R. and J.W. Loder, 1981. Dynamical aspects of shallow sea fronts. Phil. Trans. R. Soc. Lond., A302, 563-581.

Geyer, W.R., 1989. Field Calibration of Mixed-Layer Drifters. J. Atmos. Ocean. Tech. 6, $333-342$

Houghton, R.W. and C. Ho., 2001. Diapycnal flow through the Georges Bank tidal front: A dye tracer study. Geophys. Res. Letters, 28, 33-36.

Humman, J., 2005. CODAS ADCP Processing Documentation. WWW Page http://moli.soest.hawaii.edu/docs/adcp_doc/index.html.

Lough, R.G. and J.P. Manning, 2001. Tidal-front entrainment and retention of fish larvae on Georges Bank. Deep-Sea Res. II, 48, 631-644.

Lozier, M.S and G. Gawarkiewicz, 2001. Cross-Frontal exchange in the Middle Atlantic Bight as evidenced by surface drifters. J. Phys. Oceanogr., 31, 2498-2510.

Manning, J.P., R.G. Lough, C.E. Naimie, and J.H. Churchill, 2001. Modeling the effect of a slope water intrusion on advection of fish larvae: May 1995 on Georges Bank. ICES J. Mar. Sci., 58(5), 985-993.

Matthews, J.P., Fox, A.D., Prandle, D., 1993. Radar observation of an along-front jet and transverse flow convergence associated with a North Sea front. Cont. Shelf Res., 13, 109-130.

Niiler, P.P., A.S.Sybrandy, K. Bi, P.M. Poulain, and D. Bitterman, 1995. Measurements of water following characteristics of holey-sock and Tristar drifters. Deep-Sea Res., 41, 1951- 


\section{Estimates of Dispersion}

1964.

Okubo, A., 1971. Oceanic diffusion diagrams. Deep-Sea Res., 18, 789-802.

Okubo, A. 1974. Some speculations on oceanic diffusion diagrams. Rapports et ProcecesVerbaux des Reunions Conseil International pour 1'Exploration de la Mer. 167, 77-85.

Okubo, A. and Ebbesmeyer, C.C., 1976. Determination of vorticity, divergence, and deformation rates from analysis of drogue observations. Deep-Sea Res., 23, 349-352.

Pingree, R.D., Forster, G.R., Morrison, G.K., 1974. Turbulent convergent tidal fronts. J. Mar. Biol. Ass. U.K., 54, 469-479.

Proehl, J.A., D.R. Lynch, and D.J. McGillicuddy, 2005. Modeling turbulent dispersion on the Northern Flank of Georges Bank using Lagrangian particle methods. Cont. Shelf Res. 25. 875-900.

Reed, R.K., 1971. An observation of divergence in the Alaskan Stream. J. Phys. Oceanogr., 1, 282-283.

Smith, P.C., 1989. Circulation and Dispersion on Browns Bank. Can. J. Fish. Aqua. Sci., 46, $539-559$.

Sybrandy, A.L. and P.P. Niiler, 1991. The WOCE/TOGA Lagrangian Drifter Construction Manual, Univ. Calif. San Diego, SIO NO. 91-6. WOCE Report 63.

Teng, R-S., 2002. On the dispersion and diffusion near estuaries and around islands. Estuar., Coastal Shelf Sci., 54, 89-100.

Zimmerman, J.T.F., 1986. The tidal whirlpool: a review of horizontal dispersion by tidal currents. Netherlands J. Sea Res., 20, 133-154. 
Estimates of Dispersion

Table 1a. Cluster statistics for Shallow Drifters ( $<=15 \mathrm{~m})$

\begin{tabular}{|r|r|r|r|r|r|r|r|r|r|r|r|r|r|}
\hline Cluster & Cruise & Lat & Lon & $\mathrm{U}$ & $\mathrm{V}$ & $\mathrm{Ke}$ & $\begin{array}{r}\text { Ka } \\
\mathrm{c}\end{array}$ & Size & $\begin{array}{r}\mathrm{K} \\
\mathrm{x}\end{array}$ & Ky & $\begin{array}{r}\text { Ndro } \\
\mathrm{g}\end{array}$ & $\begin{array}{r}\text { Depth } \\
\mathrm{s}\end{array}$ & Nday \\
\hline 1 & SJ9505 & 40.78 & 67.56 & -9.4 & -11.3 & 222 & 78 & 46 & $\mathrm{~ns}$ & $\mathrm{~ns}$ & 2 & 15 & 1.2 \\
2 & SJ9507 & 40.78 & 67.73 & -10.3 & -10.1 & 757 & 139 & 43 & 21 & 10 & 4 & 5,15 & 3.4 \\
3 & SJ9507 & 40.79 & 68.12 & -7.8 & -0.2 & 66 & 21 & 16 & 14 & 9 & 5 & 15 & 2.3 \\
4 & OC301 & 40.64 & 67.75 & -7.3 & -3.9 & 43 & 29 & 26 & $\mathrm{~ns}$ & $\mathrm{~ns}$ & 2 & 13 & 5.4 \\
6 & OC303 & 40.80 & 67.94 & -3.7 & -4.4 & -21 & 6 & 9 & $\mathrm{~ns}$ & $\mathrm{~ns}$ & 2 & 13 & 5.5 \\
7 & OC303 & 40.69 & 68.56 & -12.7 & -7.2 & 28 & 21 & 19 & $\mathrm{~ns}$ & $\mathrm{~ns}$ & 2 & 13 & 2.6 \\
& AL980 & & & & & & & & & & & & \\
8 & 5 & 41.01 & 67.73 & -0.8 & -0.3 & 0 & 3 & 5 & $\mathrm{~ns}$ & $\mathrm{~ns}$ & 2 & 12,13 & 0.9 \\
10 & EL9905 & 41.08 & 67.52 & -2.2 & -4.6 & 193 & 80 & 42 & $\mathrm{~ns}$ & $\mathrm{~ns}$ & 2 & 8,13 & 3.0 \\
11 & EL9905 & 41.08 & 67.50 & -13.9 & -5.6 & -2 & 44 & 30 & $\mathrm{~ns}$ & $\mathrm{~ns}$ & 3 & 8,13 & 0.9 \\
12 & EL9905 & 41.07 & 67.45 & -5.6 & 0.4 & 12 & 15 & 16 & $\mathrm{~ns}$ & $\mathrm{~ns}$ & 2 & 8,13 & 2.2 \\
13 & EL9905 & 41.13 & 67.33 & -3.4 & -1.5 & -19 & 4 & 7 & $\mathrm{~ns}$ & $\mathrm{~ns}$ & 2 & 8,13 & 2.6 \\
14 & EN323 & 41.18 & 67.63 & -4.4 & 1.6 & -54 & 19 & 20 & $\mathrm{~ns}$ & $\mathrm{~ns}$ & 2 & 1 & 3.2 \\
15 & EN323 & 41.17 & 67.67 & -8.7 & -1.3 & 8 & 6 & 7 & 8 & 18 & 6 & 1 & 2.5 \\
16 & EN323 & 41.06 & 67.75 & -0.3 & 5.3 & 151 & 45 & 31 & $\mathrm{~ns}$ & $\mathrm{~ns}$ & 2 & 1 & 3.0 \\
\hline
\end{tabular}

Table 1b. Cluster statistics for Deep Drifters (>15 m)

\begin{tabular}{|c|c|c|c|c|c|c|c|c|c|c|c|c|c|}
\hline Cluster & Cruise & Lat & Lon & $\mathrm{U}$ & $\mathrm{V}$ & $\mathrm{Ke}$ & $\begin{array}{r}\mathrm{Ka} \\
\mathrm{c} \\
\end{array}$ & Size & $\begin{array}{l}\mathrm{K} \\
\mathrm{x} \\
\end{array}$ & Ky & $\begin{array}{r}\text { Ndro } \\
\mathrm{g} \\
\end{array}$ & Depths & Nday \\
\hline 5 & OC303 & 40.84 & -67.83 & -9.1 & -2.6 & 150 & 37 & 27 & ns & ns & 2 & 33 & 1.8 \\
\hline 6 & OC303 & 40.87 & -67.87 & -1.3 & -2.8 & -26 & 18 & 19 & ns & ns & 3 & 33 & 2.7 \\
\hline 7 & $\begin{array}{r}\text { OC303 } \\
\text { EL990 }\end{array}$ & 40.68 & -68.53 & -8.4 & -5.0 & 130 & 38 & 25 & ns & ns & 3 & 33 & 2.5 \\
\hline 10 & $\begin{array}{r}5 \\
\text { EL990 }\end{array}$ & 41.11 & -67.51 & -0.8 & -3.0 & 215 & 84 & 44 & ns & ns & 2 & 33 & 3.0 \\
\hline 11 & $\begin{array}{r}5 \\
\text { EL990 }\end{array}$ & 41.09 & -67.44 & -9.9 & 3.5 & 151 & 45 & 27 & ns & ns & 3 & $23,25,33$ & 0.9 \\
\hline 13 & 5 & 41.11 & -67.35 & -6.4 & -1.9 & 15 & 13 & 14 & ns & ns & 2 & 33 & 2.4 \\
\hline 14 & EN323 & 41.12 & -67.56 & -1.5 & -0.5 & 50 & 24 & 19 & ns & ns & 2 & 19.4 & 3.0 \\
\hline 16 & EN323 & 40.88 & -67.69 & -3.5 & 8.3 & 16 & 6 & 6 & 2 & 4 & 5 & $19.4,39.4$ & 0.9 \\
\hline
\end{tabular}

$\mathrm{U}=$ mean eastward velocity $\left(\mathrm{cm} \mathrm{s}^{-1}\right)$ averaged over period of cluster

$\mathrm{V}=$ mean northward velocity $\left(\mathrm{cm} \mathrm{s}^{-1}\right)$ averaged over period of cluster

$\mathrm{K}_{\mathrm{e}}=$ effective eddy diffusivity $\left(\mathrm{m}^{2} \mathrm{~s}^{-1}\right)$ includes shear effects

$\mathrm{K}_{\mathrm{ac}}=$ calculated apparent eddy diffusivity $\left(\mathrm{m}^{2} \mathrm{~s}^{-1}\right)$ includes shear effects

$\mathrm{K}_{\mathrm{x}}=$ cross-bank diffusivity $\left(\mathrm{m}^{2} \mathrm{~s}^{-1}\right)$ without shear effects where "ns" means not significant

$\mathrm{K}_{\mathrm{y}}=$ along-bank diffusivity $\left(\mathrm{m}^{2} \mathrm{~s}^{-1}\right)$ without shear effects where "ns" means not significant

Size $=$ cluster size $\lambda=3 \bar{\sigma}(\mathrm{km}$, see text $)$

Ndrog $=$ number of drifters

Depths $=$ drogue depths $(\mathrm{m})$

Ndays $=$ number of days 
Estimates of Dispersion 


\section{Figure Captions}

Figure 1. Four generations of Brightwater drifters used in this study. The $\sim 1 \mathrm{~m}$-long PVC cylinders, supported by two pairs of $10 \mathrm{~cm}$-styrofoam spheres, housed the electronics. Only the upper half of the Styrofoam spheres and GPS/VHF/ARGOS antennae extended above the water line. A $\sim 30$-cm diameter Norwegian plastic float, supporting a holey sock drogue on 3/16" plastic coated wire, was tethered to each unit by a $\sim 10-\mathrm{m}$ long polypropylene line. This configuration provided a means to absorb the wave motion and facilitated recovery. Approximately $95 \%$ of the drifters were recovered.

Figure 2. General location of each of the 16 clusters deployed over the southern flank of Georges Bank. The 60-m and 100-m isobaths are depicted.

Figure 3a. Near-surface $(<=15 \mathrm{~m})$ cluster tracks with the path of the centroid denoted in black. The vertical red bars are oriented North-South and represent 10-km scale .

Figure3b. Same as Figure 3a except showing deep (>15 m) cluster tracks.

Figure 4. Plots of $\sigma$ against time showing cluster divergence (top panel) and convergence (bottom panel).

Figure 5a. Along-bank (dashed) and cross-bank (solid) displacement $(\mathrm{km})$ from centroid vs. time (year-day) for all 14 near-surface clusters. Those noted with "C" indicate a tendency for convergence in the cross-bank direction. The cluster number is posted on each panel. 


\section{Estimates of Dispersion}

Figure 5b. Same as Figure 5a except for deep clusters.

Figure 6. Drifter displacements $(\mathrm{km})$ relative to cluster centroid, which is denoted by a black dot at the center of each panel.

Figure 7. Apparent eddy diffusivity $\left(K_{a c}\right)$ vs. cluster size $(\lambda)$ including values from DL2001 and the theoretical estimate $\left(K_{a e}\right)$ of Okubo (1971). The solid and open squares are from clusters of deep $(>15 \mathrm{~m})$ drogued and shallow $(<=15 \mathrm{~m})$ drogued drifters, respectively.

Figure 8. Mean cross-bank displacement of drifters relative to the cluster centriod (dashed) and cross-bank velocity of the cluster centriod (solid) vs. time (yearday). The curves in all panels indicate a periodic convergence/divergence with the offbank/onbank tide.

Figure 9. Modeled (solid lines) and observed (dashed lines) cross-bank (blue) and along-bank (magenta) displacement relative to centroid of cluster \#3. The modeled displacements closely reproduce the tidal oscillations exhibited in the observed displacements.

Figure 10. T/S relations of four patch-following operations conducted on cruises SJ9505, SJ9507, OC301, and OC303. The number of days, maximum distance to drifter, and the mean change in sigma-t per day (italicized) are posted in each panel. The black sigma-t contours (one for each CTD) are values calculated at the drogue depths. Each panel represents the result of following a single drifter. 


\section{Estimates of Dispersion}

Figure 11. Cross-frontal density structure (contoured $\sigma_{\mathrm{T}}$ ) with cross-bank trajectory (bold arrow) of each drifter as observed within three days of CTD section. The thin arrow represents the scaled cross-bank distance that a drifter would have traveled over a six-day period centered on the time of the CTD section. The origin of the x-axis is at each section's maximum cross-bank density gradient at 30m depth. The depth of each arrow, while offset slightly to prevent overlaps, indicates the approximate depth of the holey sock drogue. The two numbers posted on the onbank side represent the cluster ID and the cluster's mean distant from the front.

Figure 12. Daily average change in cross-bank cluster extent vs. mean distance from the front. The values indicate cluster convergence within $10 \mathrm{~km}$ from the front and divergence of clusters further from the front $(>13 \mathrm{~km})$. This analysis is done for cases where CTD transects were taken through clusters and does not include clusters with less than a total of 6 drifter days. The lone drifter that escaped in the case of cluster 2 (see Figure $3 a$ 's $2^{\text {nd }}$ panel) was also removed from this calculation. 